Business and Economics | Claus A Foss Rosenstand

\section{A canvas for a digital ecosphere}

Digital Hub Denmatk attracts digital talents, investors, and customers to Denmark. Digital from A Foss Rosenstand helping organisations achieve exponential growth by technologies. While still in its early stages, this action research programme has that tech-businesses in areas strongholds. Seven digital ecosystems - Fin-tech, Healthtech, Agro-tech, and Ed-tech have been identified, and form the Danish Digital Ecosphere.

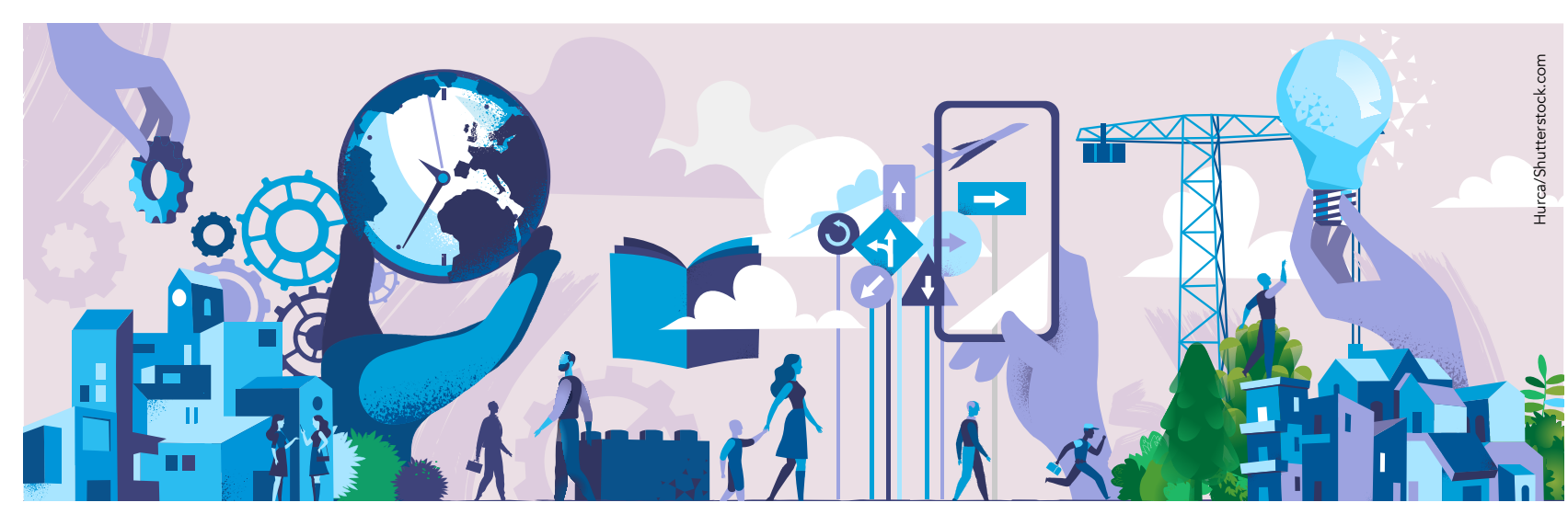
goods and services that they replace. of innovation that a digital disruptive technology's price peformance is o exponential growth trajectory.

a value-network of different stakeholders, such as suppliers, and government agencies, together with all the respective technologies. Each element of the ecosystem affects and is affected by the others, as in a biological ecosystem. This creates a constantly element must fit to survive. A sustainable ecosystem creates synergy with each participant gaining more value than any of the individual participants would be able to do outside of the ecosyste To succeed, ecosystems can be reconfigured by separating, combining elocating, adding, and removing

describes digital ecosystems as marketdriven, bottom-up phenomena, unlike politically implemented top-down cluster organisations. Consequently, the value proposition of the existing

\section{DIGITAL ECOSYSTEMS} customers, trading partners, competitors, Digital disruptive innovation radically and industries function. This alters Hub Denmark Professor, leveraging digital disrup produced a canvas to support digital ecosystems made up of tech, Robotics, Crea-tech, PropProfessor Rosenstand adds to the theory

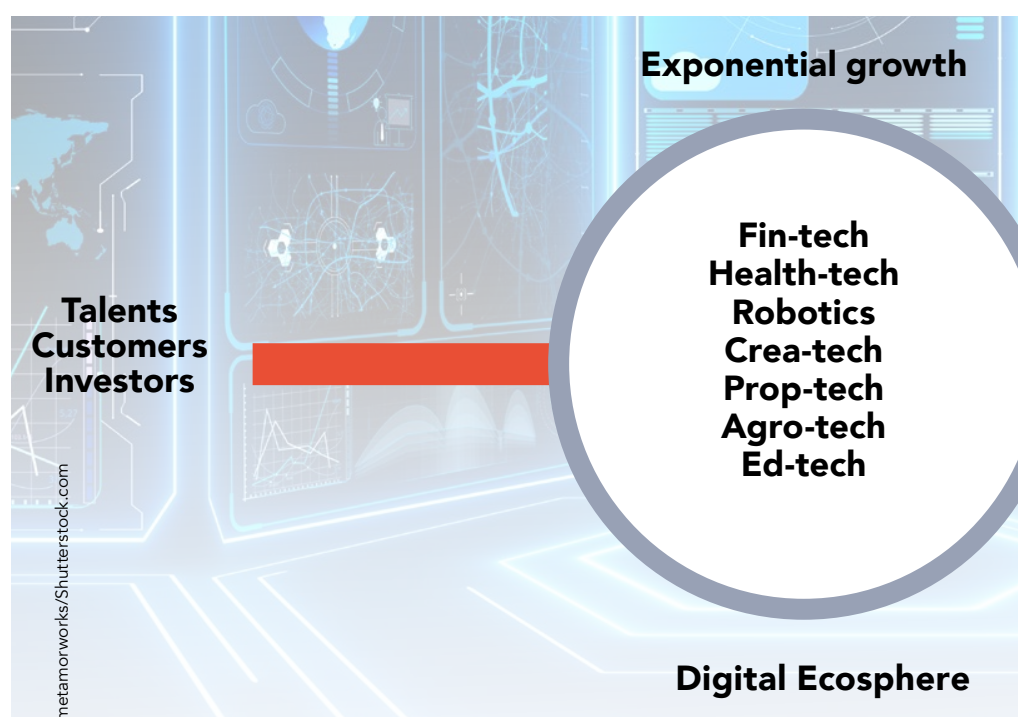

should involve representatives from the private sector. Private-public partnerships, with key partners from both the most inclusive solution.

Existing research demonstrates the design of model using the Business Model Canvas, a strategic business tool used to visualise all the building blocks such as infrastructure, customers, and finance - that are required to develop new business models and document existing ones. Digital business characteristics are also described for a fully decentralised architecture on a general level. These mention that such ecosystems should not have a single point of nor should they be reliant on an individual actor$$
\text { or situation. They }
$$
scalable and robust.

\section{A RESEARCH GAP}

Prossor Rosenstand explains that since digital ecosystems cannot be created top-down, they must be identified and then selected for support. Having carried out a thorough review of ecosystem literature and system theory, he identified a research gap in the form of a canvas model to select, combine, and cultivate multiple digital ecosystem practical perspective, reseal into practical perspective, resea chrothe

\section{Professor Rosenstand's novel digital} ecosphere canvas is constituted

by a series of interlinked market verticals and horizontals.

action research methodology. Action seeks transformative change throug a combination of research, action, and participation. It involves a cyclic proces of action and critical reflection. The researcher draws on the understanding developed during the earlier cycles and continues to refine procedures, data, and interpretation throughout subsequent solutions, driven by the rationalities that

IDENTIFYING DIGITAL ECOSYSTEMS A Startup Genome report, funded by ecosystems - Fin-tech, Health-tech, Robotics,
Crea-tech, Prop-tech, Agro-tech, and Ed-tech tified, and form the Danish

Digital Hub Denmark, was the starting digital ecosystems. This of sultable Denmark's position in the global startup ecosystem lifecycle. The report identified our digital ecosystems where Denmark has a stronghold: Fin-tech, or finance solutions to augment, streamline and digitise financial services; Robotics, developing intelligent robots, drones and automation solutions; Agro-tech, providing intelligent solutions for the agricultural and food sectors; and Edech, developing digital solutions for education eg, using technologies such Al, and natural language processing Three further digital ecosystems that national stronghold were also created creative industries movies forming a Crea-tech (creativity technology) ecosystem; actors from the property industry, construction, and real estate forming a Prop-tech (property technology) ecosystem; and actors from Health-tech ecosystem, (n)

IGITAL ECOSPHERE

As illustrated in Figure 1, these seven Rosytens form what Professor Rosentand forms a 'digital ecosphere'. en explanshow an ecosphere is 


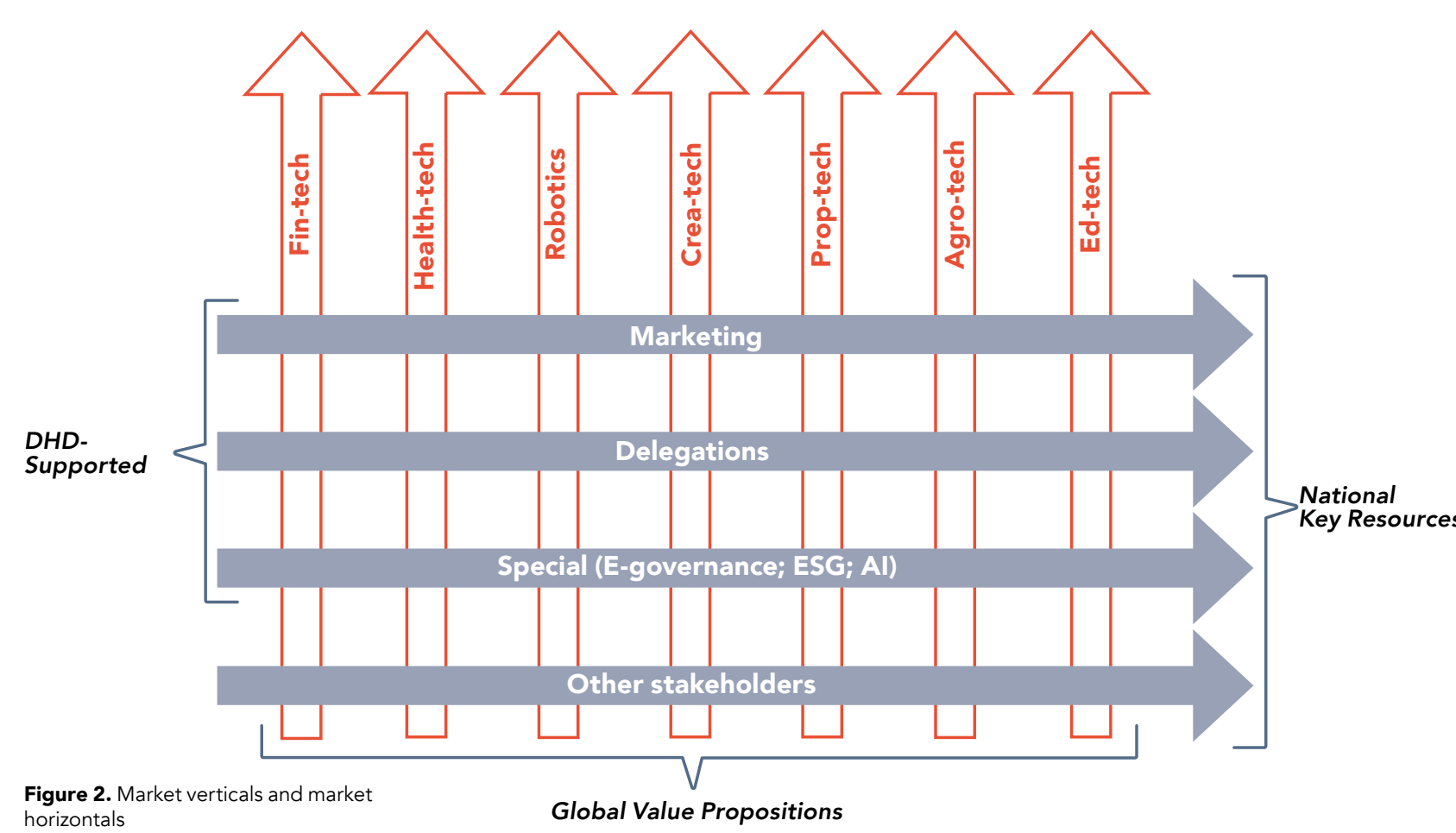

Figure 2. M M
horizontals

Global Value Propositions

ecosystems. Digital ecosystems are social systems, so system theory can digital ecosphere is structurally closed to its surroundings because it is selforganised and self-structured, it is also operatively open to its surroundings in terms of communication. He draws an analogy between biological and digital ecospheres. The earth is a biological ecosphere that is open to energy from the sun and waves and results in multiple ecosystens gith evolutionary the Danish digital the Danish digital
ecosphere is open to the energy that comes from talents,

customers, and investors, and currenty results in the seven digital ecosystems with exponential growt

\section{processes, agility, management, digital} and effective to select, combine, and cultivate digital ecosystems in coherent digital ecosphere.

the co-creation process of forming a digital ecosphere. Professor Rosenstand has discussed and developed the canvas with input from the ecosystem innovation managers, Digital Hub Denmark co-workers, and other These digital ecosystems are identified innovation researchers. The Digital in terms of their size, turnover, and Ecosphere Canvas borrows conceptually from the mar a milin not con of the biological ecosphere in which the earth is reliant upon the Innovation managers must have a global, $\begin{gathered}\text { mutual interactions } \\ \text { of numerous }\end{gathered}$ open, and integrative mindset, where ecosystems for all national businesses are considered growth. Instead potential ecosystem participants rather Rosenstand's novel digital competitors.

criteria. The ecosystem should be formally organised as a nationwide not-for-profit association. It should be such as a cluster director or CEO. Finally, the 'innovation managers must

The digital tech-businesses included the digital ecosphere share the aim of achieving exponential growth through common value proposition of digita ransformation, leveraged by digital disruptive technologies. Accordingly, they have a shared agenda with respect to business development regarding, eg, strategy, organisation, technology, sales, marketing, partnerships, busin dintegrative

\section{A CANVAS FOR A}

DIGITAL ECOSPHERE ecosphere canvas
is constituted by series of interlinked market verticals and horizontals.

Figure 2 shows how market verticals are made up of those digital ecosystems which maintain global value propositions. More specifically, these value propositions are linked by digital transformations, though each of these transformations will pertain to a specific domain (an example might be a digital financial sector)

Market horizontals, on the other hand, will meet the requirements of a divers array of businesses across a multitude cindustries. This will require the sha and key resources across numerous ecosystems. The canvas is open to other horizontal players regarding such things as investment, business models, accelerators, etc. The digital ecosphere canvas can be utilised in support of exponential growth and can cultivate further digital ecosystems within the digital disruptive domain. Importantly, the canvas highlights where initiatives which are publicly supported might have an influence on individual ecosystems.

An important objective for future research will be to assess how Professor Rosenstand's canvas might transcend to digital sector and work in relation potentially even non-digital industries. Professor Rosenstand notes, however, that digital connection might be essential for the sort of ecosystem reconfiguration he is thinking of.

\section{SUPPORTING THE}

DIGITAL ECOSPHERE

Digital Hub Denmark supports

the digital ecosphere by matching

private companies, researchers, techentrepreneurs, and students to the development of new digital products, services, and business models. The hub delivers marketing, delegations, and special initiatives, including campaigns to attract digital talents, delegations to attract customitual) aso provides a mapping of the digital ecosphere's more than 1,000 digital tech-businesses to attract talent, investors, and consumers. Digital Hub Denmark also hosts meetings where innovation managers from all seven ecosystems join the CEO of Digital Hub Denmark, Professor Rosenstand, and special guests to plan the progress of the Danish digital ecosphere along the trajectory to the attraction phase, by selecting, combining, and cultivating national digital ecosystems where Denmark has a global stronghold. The aim is for Denmark to have significantly industries represet shares in the digistres represented by the Danish cigital ecosphe

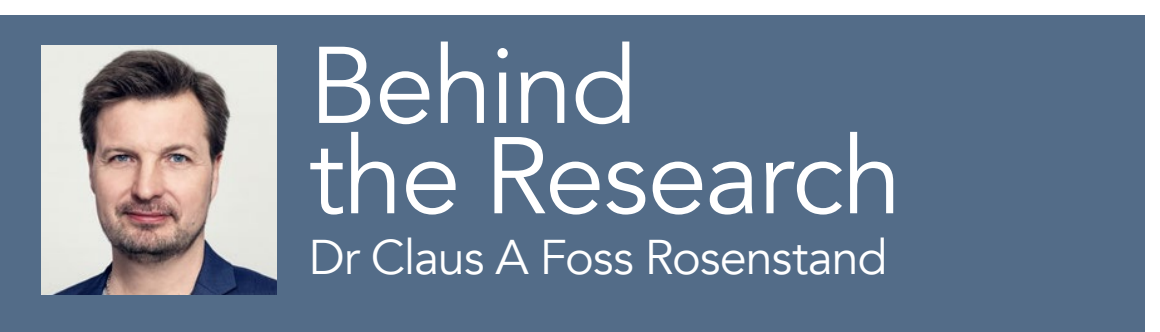

E: cr@hum.aau.dk E: claus.r@digitalhubdenmark.dk T: +4520516004 W: www.aau.dk $\mathbf{W}$ : www.digitalhubdenmark.dk

\section{Research Objectives}

Professor Claus A Foss Rosenstand is helping organisations achieve exponential growth by leveraging digital disruptive technologies.

\section{Detail}

Address

Nordtoft 30

9000 Aalborg

Digital Hub

Denmark

ra

Digital Hub Denmark Professor Claus A Foss Rosenstand PhD is Professor t) Aalborg University in Denmark, Thought Leader at Digital Hub Denmark, entrepreneur, author, and professional board member.

\section{References}

Rosenstand CAF, (2021) Selecting, Combining, and Cultivating Digital Ecosystems in a Digital Ecosphere. In: Schallmo, DRA, Tidd, J, (eds) Digitalization. Management For P. Ifessionals series. Springer. doi. 2021]

\section{Personal Response}

What has been the most rewarding outcome of your research with Digital Hub Denmark so far?

II The governance of the digital ecosphere including the Steering

Committee of Denmark's Digital Ecosphere and associate workgroups

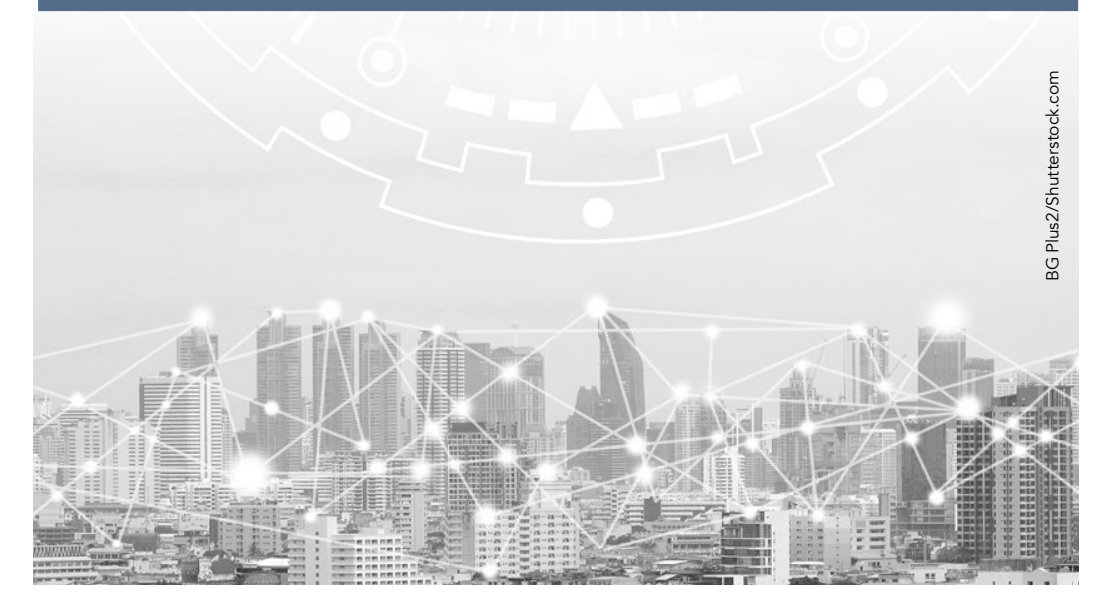

